\title{
Crystallization Behaviors of Slags through a Heat Flux Simulator
}

\author{
H. G. RYU, ${ }^{1,2)}$ Z. T. ZHANG, ${ }^{1,3)}$ J. W. CHO, ${ }^{2)}$ G. H. WEN ${ }^{4)}$ and S. SRIDHAR ${ }^{1)}$ \\ 1) Department of Materials Science and Engineering, Carnegie Mellon University, Pittsburgh, PA 15213 USA. E-mail: \\ sridhars@andrew.cmu.edu 2) POSCO, Cheonnam 547-711 South Korea. \\ 3) Department of Energy and Recourses Engineering, College of Engineering, Peking University, Beijing 100871 P.R. China. E- \\ mail: zuotaizhang@coe.pku.edu.cn \\ 4) Department of Metallurgy, College of Materials Science and Engineering, \\ Chongqing University, Chongqing 400044 P.R. China.
}

(Received on February 10, 2010; accepted on April 27, 2010)

\begin{abstract}
This paper investigates how the basicity and alumina content in synthetic slags influence the crystallization behavior that takes place in a heat flux simulator for mold slags. The purpose is to elucidate the variation in crystallization behavior for model slags that are expected to be glassy, partly crystalline and fully crystalline in order to correlate the changes in heat flux to the dynamic solid evolution that occurs in the simulator. Three levels of alumina content $(3,15$ and $25 \mathrm{wt} \%)$ were chosen to investigate the heat transfer behavior through slag film which have different tendency of reaction with molten steel during continuous casting of high aluminum containing Transformation Induced Plasticity (TRIP) steels. A Confocal Scanning Laser Microscopy (CSLM) was used to develop TTT diagrams for the slags. XRD and SEM were also used to analyze the micro-structures of the crystalline phases.

The measured heat fluxes through the mold slags tested were found to increase, as the crystallinity of the slag film decreased with decreasing basicity and alumina content. It was found that the crystallization temperature increased, while the incubation time for crystallization decreases with increasing basicity and alumina content. The increase in alumina content induced the precipitation of $\mathrm{CaF}_{2}$ during cooling process and hence a change in the crystalline phase from $\mathrm{Ca}_{4} \mathrm{Si}_{2} \mathrm{O}_{7} \mathrm{~F}_{2}$ to $\mathrm{Ca}_{2} \mathrm{Al}_{2} \mathrm{SiO}_{7}$.
\end{abstract}

KEY WORDS: mold slag; TRIP steel; crystallization behavior; heat flux.

\section{Introduction}

It is well known that mold slags play a key role in the continuous casting of steel by providing lubrication and controlling heat transfer. This is accomplished by controlling the thickness and micro-structure of the solid phases that form in the slag film between the copper mold and strand. ${ }^{1)}$ The slag film is generally composed of three sublayers, a glassy layer close to the copper mold due to a fast cooling rate, a crystalline layer located in the center where the cooling rate and temperature are favorable to form the crystals, and a liquid film in contact with the steel. ${ }^{2)}$ Generally, the crystals could be present inside both the solidglassy- and liquid-layers, and the presence of crystals in the liquid layer would increase the friction between the mold and strand, while the crystals present in solid layer play a role in decreasing heat transfer rate by scattering radiation or forming pores due to the shrinkage during crystal formation. ${ }^{3)}$ The decrease of heat transfer may help to alleviate the longitudinal cracking problem which occurs due to the thermal mismatch between ferrite and austenite phases. ${ }^{4)}$ It is therefore important to understand how the crystallization influences the heat transfer rate. Regarding crystallization, a number of methods have been used to determine the crystallinity of mold slags, which include Differential Thermal Analysis (DTA), ${ }^{5)}$ Hot Stage Microscopy such as Confocal Scanning Laser Microscope (CSLM), ${ }^{6)}$ and Single (or Dou- ble) Hot Thermocouple Technique (SHTT or DHTT). ${ }^{7}$ ) These methods can determine the crystallization properties of mold slags through the development of Time Temperature Transformation (TTT) or Continuous Cooling Transformation (CCT) diagram. They can however not determine how the crystallization influences the heat flux quantitatively. In view of the disadvantages of these methods, Ohmiva, ${ }^{8)}$ Yamauchi ${ }^{9)}$ and Cheng ${ }^{10)}$ measured the heat flux or overall thermal resistance of a parallel-sided plate filled with mold slag using one dimensional heat transfer method. However, it is hard to control one dimensional heat transfer during measurement of the heat flux, and to measure the heat flux in non-steady state heat transfer by this method. Vermeulen ${ }^{11)}$ used the copper finger method to study how the chemical compositions of mold slags affect crystallization behaviors and heat transfer, and determined the heat transfer rate through measuring the temperature of the copper tube. Wen ${ }^{12)}$ developed a method to measure the heat flux through measuring the temperature difference of inlet and outlet of water flow in copper sensor. This method can determine the heat flux and the thickness of slag film simultaneous, and the comparison of slag film with that from steel plant indicated that it can simulate the practical continuous casting process. To the knowledge of authors, no systematic investigations have been carried out with a combination of two methods. Therefore, the first purpose of this investigation was to carry out an investigation on the per- 
formance of a mold slag simulator that was developed by Wen ${ }^{12)}$ by using model mold slags whose crystallization behavior can be predicted. The second purpose was to analyze the heat fluxes with TTT diagrams developed using CSLM method.

In recent years, advanced high strength steels (AHSS) have attracted much attention to be used as car bodies due to its excellent combination of high strength and ductility, ${ }^{13-15)}$ which necessitate the development of AHSS steels for continuous production in steel plants. However, there are several problems that need to be overcome and some are related to the high amount of reactive elements in these alloys. ${ }^{16,17)}$ For example, it is difficult to control the alloy composition during continuously casting of some grades of AHSS, such as TRIP steels, as a result of reactions between the mold slag and the melt, involving the formation of alumina. Critical properties of the mold slag can change during casting as a result of alumina pick-up, ${ }^{18,19)}$ when casting high aluminum TRIP steel and this could cause surface cracks on the slab or sticker break-outs. It is therefore necessary to study how to suppress the reactions between the mold slag and the melt. One possible method to accomplish this is to increase the alumina content in the mold slag. The details of the incorporation of alumina in slags is however not completely known and depending on this the alumina content in mold slag could result in changes in the key thermophysical properties of mold slag, such as viscosity, crystallization and thermal conductivity. The third purpose of this work was therefore to characterize slag crystallization and heat transfer as a result of an increasing alumina content.

\section{Experimental}

The technical approach that was undertaken involved measuring the heat flux during immersion of an inverted mold into the simulator and comparing the resulting solid layers formed with TTT diagrams that are established through in-situ CSLM observations and metallographic characterization using XRD and SEM.

\subsection{Materials}

Table 1 lists the measured chemical compositions of mold slags by X-ray fluoroscopy (XRF) that were manufactured for the current experiments. No. 1 and No. 2 slag were mixed with regent grade $\mathrm{CaO}, \mathrm{SiO}_{2}, \mathrm{Al}_{2} \mathrm{O}_{3}$ and $\mathrm{CaF}_{2}$ and pre-melted at $1400^{\circ} \mathrm{C}$. No. 3 slag is a commercial mold

Table 1. Designed mold fluxes for experiments.

\begin{tabular}{|l|r|r|l|l|l|}
\hline & No1 slag & No2 slag & No3 slag & $\begin{array}{l}\mathrm{No3}+ \\
5 \mathrm{Al}_{2} \mathrm{O}_{3}\end{array}$ & $\begin{array}{l}\text { No3+ } \\
15 \mathrm{Al}_{2} \mathrm{O}_{3}\end{array}$ \\
\hline Basicity & 1.59 & 1.50 & 0.95 & 0.95 & 0.95 \\
\hline $\mathrm{SiO}_{2}$ & 26.00 & 31.11 & 28.37 & 26.80 & 23.65 \\
\hline $\mathrm{CaO}$ & 41.46 & 46.52 & 27.08 & 25.58 & 22.57 \\
\hline $\mathrm{MgO}$ & 0.33 & 0.38 & 9.89 & 9.34 & 8.24 \\
\hline $\mathrm{Al}_{2} \mathrm{O}_{3}$ & 25.39 & 15.42 & 3.05 & 8.05 & 18.05 \\
\hline $\mathrm{Fe}_{2} \mathrm{O}_{3}$ & 0.05 & 0.07 & 0.35 & 0.33 & 0.29 \\
\hline $\mathrm{MnO}_{2}$ & 0.01 & 0.01 & 0.04 & 0.04 & 0.03 \\
\hline $\mathrm{P}_{2} \mathrm{O}_{5}$ & 0.03 & 0.04 & 0.03 & 0.03 & 0.03 \\
\hline $\mathrm{Na}_{2} \mathrm{O}$ & 0.23 & 0.19 & 10.23 & 9.66 & 8.53 \\
\hline $\mathrm{K}_{2} \mathrm{O}$ & 0.01 & 0.02 & 0.03 & 0.03 & 0.03 \\
\hline $\mathrm{F}$ & 9.68 & 9.71 & 11.07 & 10.46 & 9.23 \\
\hline Property & Crystallized & $\begin{array}{l}\text { Medium } \\
\text { Crystallized }\end{array}$ & Glassy & - & - \\
\hline
\end{tabular}

slag that is used to cast high Al containing TRIP steel. $\mathrm{Al}_{2} \mathrm{O}_{3}$ was added into No. 3 slag for studying the influence of $\mathrm{Al}_{2} \mathrm{O}_{3}$ content on heat flux and crystallization.

Slags were designed or used for studying the crystalline tendency and the heat flux change according to the basicity and $\mathrm{Al}_{2} \mathrm{O}_{3}$ content. The reason for using a low $\mathrm{CaO}$ content in No. 3 slag was to obtain a low basicity slag.

\subsection{Experimental Methods}

A confocal scanning laser microscope (CSLM) schematically shown in Fig. 1 was used in the present experiments. The principle of CSLM has been described in detail in the previous papers. $^{20,21)}$ The heating and cooling processes were controlled by a computer program. About $10 \mathrm{mg}$ slag was mounted on the top of a Pt plate, and heated to $1500^{\circ} \mathrm{C}$ at a heating rate of $30^{\circ} \mathrm{C} / \mathrm{s}$ and was maintained isothermally for $60 \mathrm{~s}$ to eliminate the bubbles and homogenize the slag. This was followed by a rapid cooling to a pre-set experimental temperature at a cooling rate of $80^{\circ} \mathrm{C} / \mathrm{s}$ and was maintained there for 5 to $30 \mathrm{~min}$ to observe crystallization (or the lack thereof). The sample images were continuously recorded and the onsets of crystallization temperatures and times were evaluated for constructing the Time-Temperature-Transformation (TTT) diagrams.

The heat transfer through solid slag layer was quantitatively measured through an experimental setup which was designed by Wen and his research group at Chongqing University. ${ }^{12)}$ Figure 2(a) schematically shows the experimental setup. The heat flux through the solid slag layer can thus be calculated according to the following equation,

$$
q=W \cdot C \cdot\left(T_{\mathrm{B}}-T_{\mathrm{A}}\right) /(1000 F) .
$$

where $q$ is the heat flux through the solid slag layer $\left(\mathrm{Mw} / \mathrm{m}^{2}\right), W$ is the amount of water flowing through copper simulator $(\mathrm{kg} / \mathrm{s}), T_{\mathrm{A}}, T_{\mathrm{B}}$ are the water temperature of inlet and outlet, respectively $\left({ }^{\circ} \mathrm{C}\right), F$ is the effective surface areas of copper simulator $\left(\mathrm{m}^{2}\right)$ and $C$ is the heat capacity of water $\left(\mathrm{kJ} / \mathrm{kg} /{ }^{\circ} \mathrm{C}\right)$. In order to simulate the cooling rate in the copper mold, the flow rate of the cooling water was maintained at $0.30 \mathrm{~m}^{3} / \mathrm{h}$ under the present experiment. When the copper simulator was immersed into the liquid slag, the temperature difference between the outlet and inlet or heat flux shows three significant stages which is schematically shown in Fig. 2(b). In the initial stage $\left(0-t_{1}\right)$, the temperature dif-

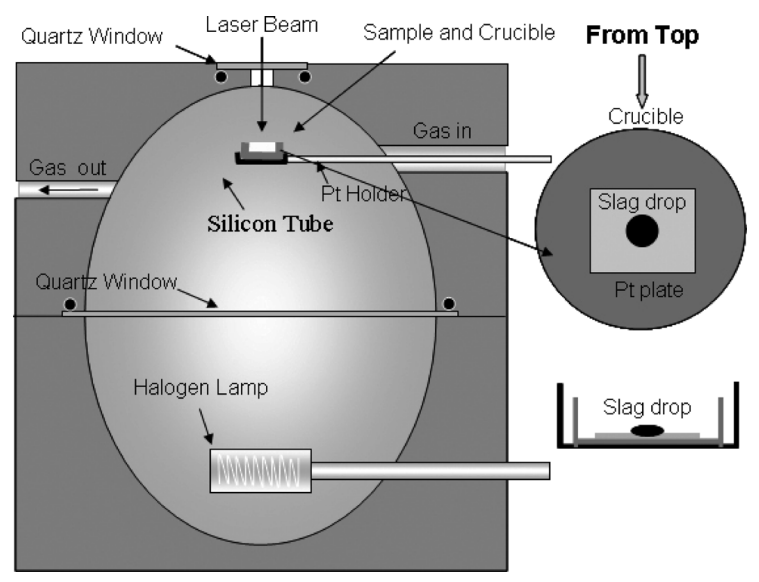

Fig. 1. Confocal scanning laser microscopy (CSLM). 
ference increases quickly to reach the maximum value, suggesting the heat transfer between the liquid slag and copper simulator. During the second stage $\left(t_{1}-t_{2}\right)$, the temperature difference shows the quick decrease, and this is indicative of the solid slag layer forms on the copper simulator and its thickness increases with time, the crystallization may occur during this stage. In the last stage, the temperature difference decreases very slowly, and this may suggest that the solid slag layer grows slowly or further crystallization of solid slag layer occurs. These are to be confirmed in this study. A series of experiments were carried out using this setup, and the experimental results indicted that the thickness of slag film is $1-5 \mathrm{~mm}$ when the time reaches $t_{2}$. This is consistent with the thickness of slag film obtained from the operating continuous casting molds. ${ }^{22)}$ The average heat flux between $t_{1}$ and $t_{2}$ is used to present the ability of the slag to transfer heat. The time $t_{1}$ is easily determined from the measured data but the time of $t_{2}$ must be evaluated as well in order to compare the heat transfer ability of slags, $t_{2}$ can be determined with operating conditions of real continuous casting.

The morphologies of precipitated crystals in the slag were examined by using a Philips XL Field Emission Scanning Electron Microscope (SEM). The cross sections were prepared by mounting in liquid epoxy resins, holding under vacuum for $15 \mathrm{~min}$ to remove the bubbles, and then reapplying atmospheric pressure. The solidified epoxy containing the specimens was subsequently cut, ground, polished, and etched in HF acid for $30 \mathrm{~s}$. Pt was sputtered onto the

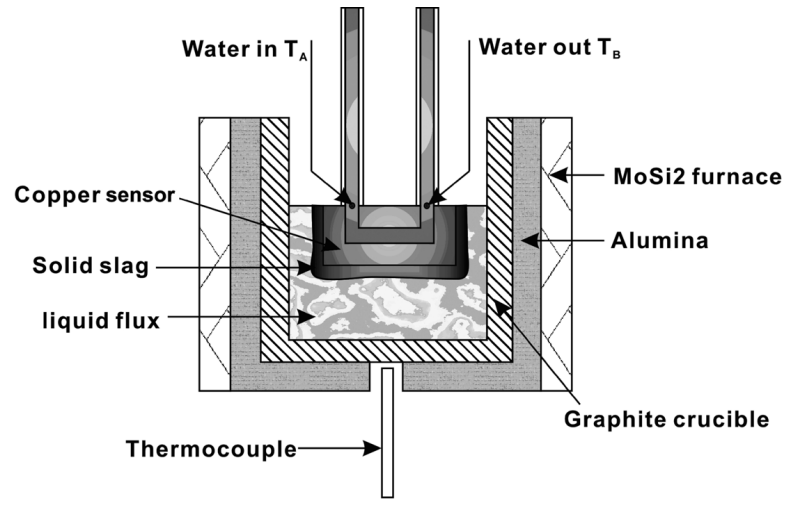

(a)

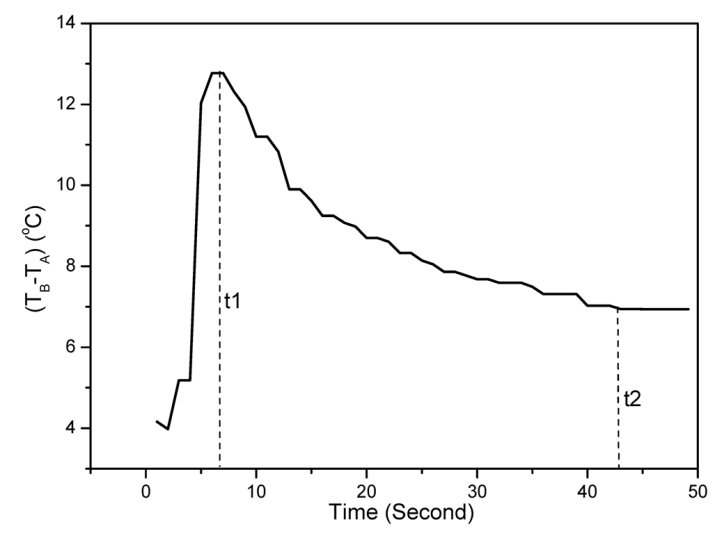

(b)

Fig. 2. (a) The experimental set-up of heat flux simulator. (b) A schematic diagram of relationship between temperature difference and immersion time. sections which were examined in an SEM equipped with an energy dispersive X-ray detector (EDS; INCA, Oxford Instrument). The accelerating voltage determining the energy and wavelength of electrons in the electron beam was $20 \mathrm{kV}$. The resolution in the secondary electron mode at $20 \mathrm{kV}$ is $3.5 \mathrm{~nm}$ at a working distance of $10 \mathrm{~mm}$.

\section{Results and Discussions}

\subsection{TTT Diagram Measurements}

Mold fluxes contain the volatile components, and this might result in the change of chemical compositions during CSLM observations. The main vapor species are $\mathrm{SiF}_{4}, \mathrm{SiO}$, $\mathrm{Na}_{2} \mathrm{~F}_{2}, \mathrm{CaF}_{2}, \mathrm{AlOF}, \mathrm{AlF}_{3}$ under the experimental temperature ranges, and their vapor pressures change in the range of $10^{-6}$ to $10^{-9}$ atm with varying temperature and chemical compositions. ${ }^{23)}$ Analysis indicated however that the evaporation rate is very low when the experimental temperature is lower than $\left.1400^{\circ} \mathrm{C}^{24}\right)$ Therefore, the evaporation is expected to be low during the CSLM observations. Unfortunately, the CSLM samples were of too small a size to verify the chemistry through chemical analysis after the experiments.

Imaging of slag crystallization in the CSLM under isothermal conditions were carried out in the temperature range of $850-1300^{\circ} \mathrm{C}$ and based on the results TTT diagrams for the observed onset of crystallization were generated. Figure 3 shows an example of CLSM images for slag No. 1 used to draw the TTT diagrams, which gives the initial stage and growth of crystals at the experimental temperature of $1150^{\circ} \mathrm{C}$. It can be seen that the columnar dendrite crystals formed along the edge of liquid drop and grew toward the centre. Onset of crystallization were documented from the observations such as those shown in Fig. 3 at different isothermal temperatures and the results were used to construct the TTT diagrams, as shown in Fig. 4. The diagrams for slags No. 1 and No. 2 show a half " $C$ " shape. A certain amount of crystals were formed during the

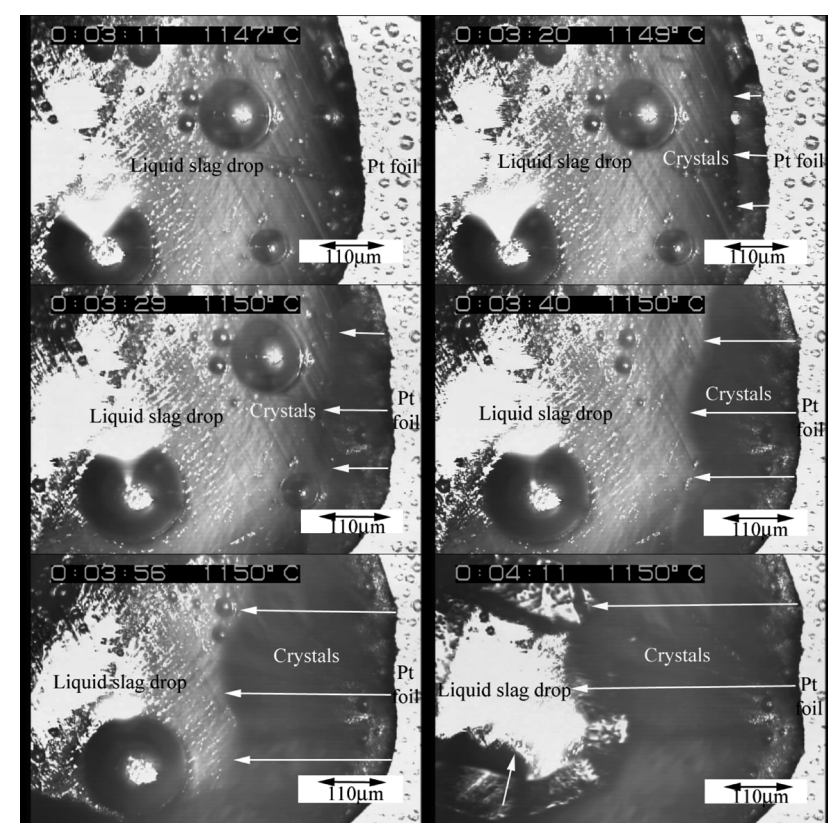

Fig. 3. Crystal growth of No. 1 slag at annealing temperature $1150^{\circ} \mathrm{C}$. 

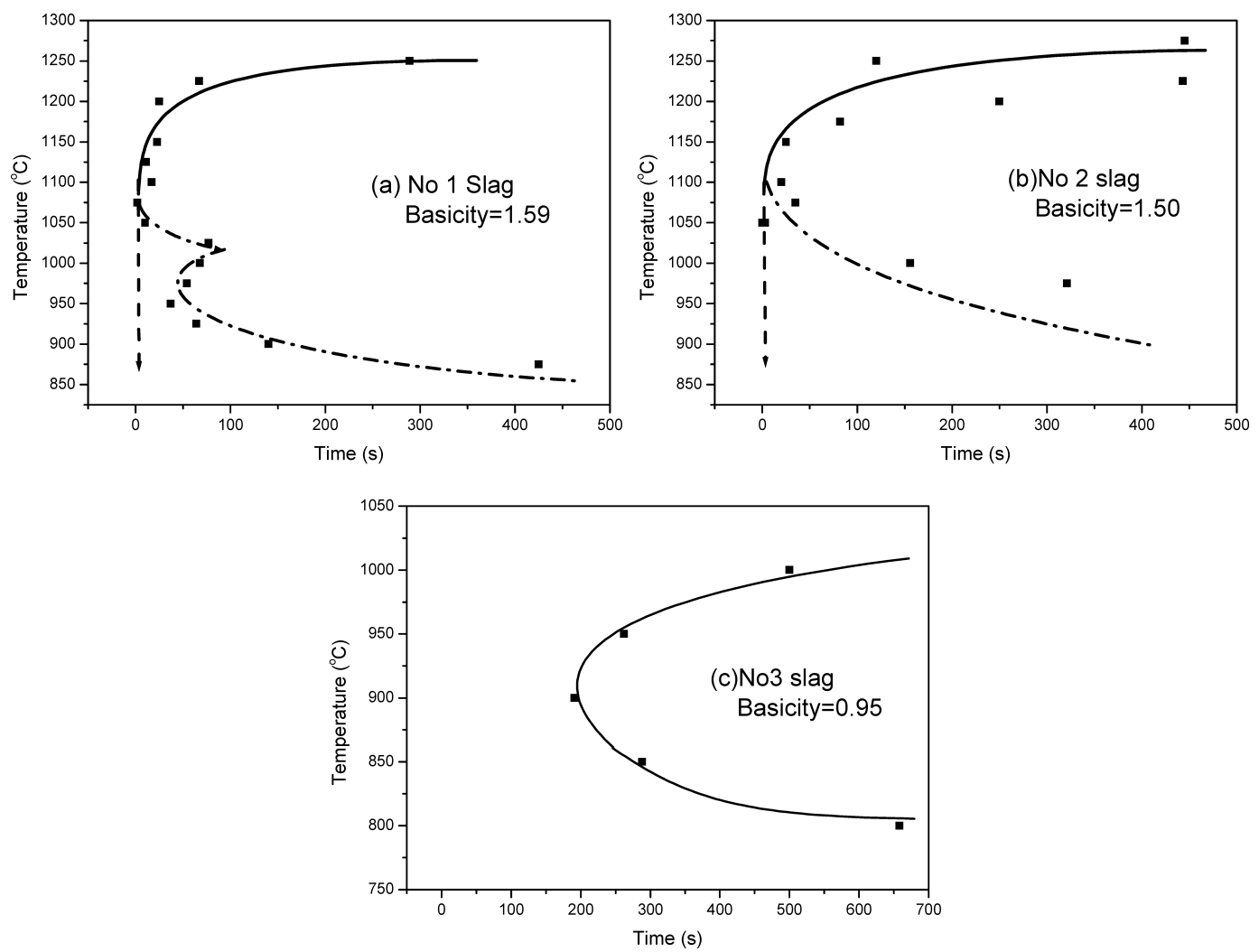

Fig. 4. TTT diagrams of (a) No. 1 slag, (b) No. 2 slag and (C) No. 3 slag.

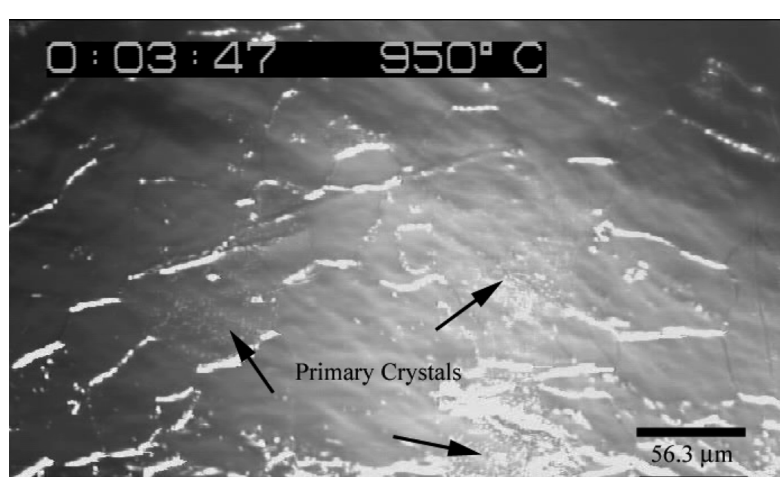

(a)

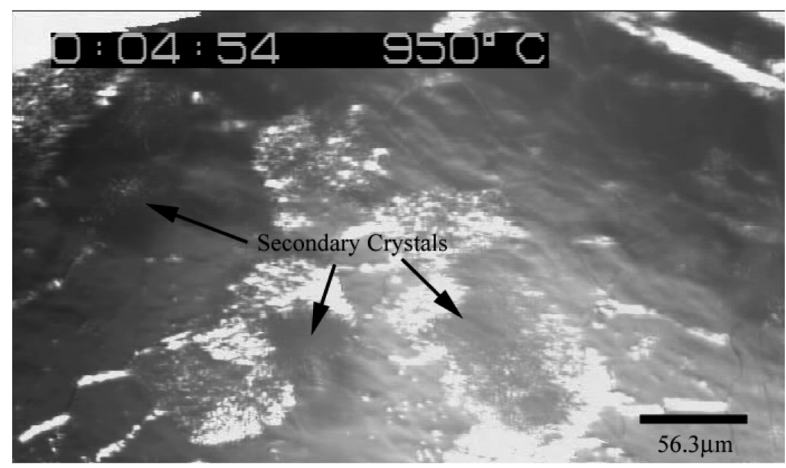

(b)

Fig. 5. The (a) primary crystals and (b) the secondary crystals formed during the cooling process for No. 1 slag at $950^{\circ} \mathrm{C}$.

cooling process when the temperature was below $1125^{\circ} \mathrm{C}$ and $1100^{\circ} \mathrm{C}$ for slag No. 1 and No. 2, respectively. Figure 5 gives the CSLM images showing the primary and second- ary crystals formed during the cooling process. It is noted that the primary crystals do not grow with time. It should be pointed out that the precipitated phases during cooling processes may have a significant effect on the subsequent crystallization: 1) the crystals may act as heterogeneous nucleation sites, and 2) the chemical composition of slag melt correspondingly changes, and this will be discussed in the following paragraph. The onset of formation of secondary crystal was also documented and labeled in Fig. 4 with dashed lines. The TTT curve for slag No. 3 shows a full " $C$ " shape with the nose temperature as $900^{\circ} \mathrm{C}$ and a singly type of crystals were observed. It is noteworthy that no precipitation was observed for sample No. 3 above $1025^{\circ} \mathrm{C}$ or below $775^{\circ} \mathrm{C}$ for times up to $1 \mathrm{~h}$. The crystallization temperature and ranges as well as incubation time decreased with decreasing basicity and alumina content.

In order to study the variation of precipitated phases and the crystal morphologies at different quenching temperatures, the slag drops for slag No. 1 after the TTT diagrams measurement at different temperatures were quenched and analyzed by SEM. Figure 6 shows the SEM images and EDS results of quenched slag No. 1 at $1200^{\circ} \mathrm{C}, 1050^{\circ} \mathrm{C}$ and $925^{\circ} \mathrm{C}$, respectively. It can be seen that a dendritic crystalline phase was formed and some particles existed between dendrite tips for slag No. 1 quenched from $1200^{\circ} \mathrm{C}$ (Fig. 6(a)) and $925^{\circ} \mathrm{C}$ (Fig. 6(c)), while rod-shape crystals had formed for slag No. 1 quenched from $1025^{\circ} \mathrm{C}$ where the crystal size was found to be very fine (Fig. 6(b)). According to the TTT diagram (Fig. 4(a)), very fast crystallization was noticed for slag No. 1 at $1200^{\circ} \mathrm{C}$ and at $925^{\circ} \mathrm{C}$, while the condition at $1025^{\circ} \mathrm{C}$ was not favorable to form the crystals. EDS results (Figs. 6(a) and 6(b)) indicated that $\mathrm{Ca}$ does not co-exist with $\mathrm{O}$, but co-exist with $\mathrm{F}$, and the el- 


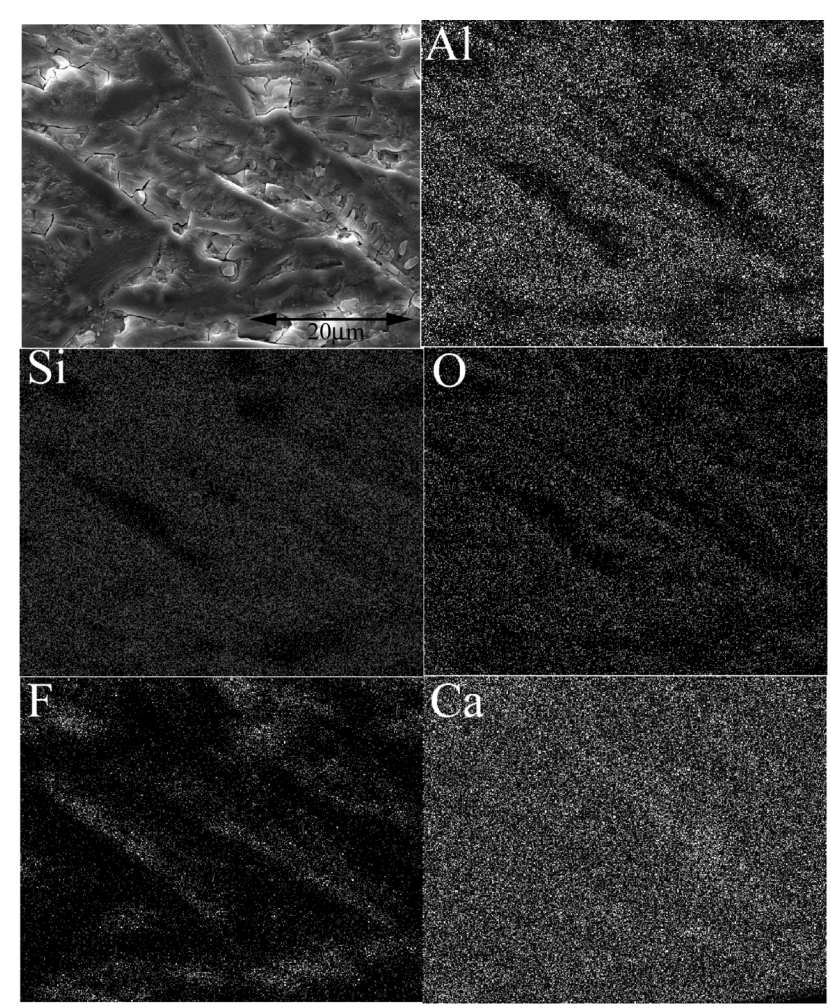

Fig. 6. SEM observations of cross-sections of slag 1 annealed at (a) $1200^{\circ} \mathrm{C}$
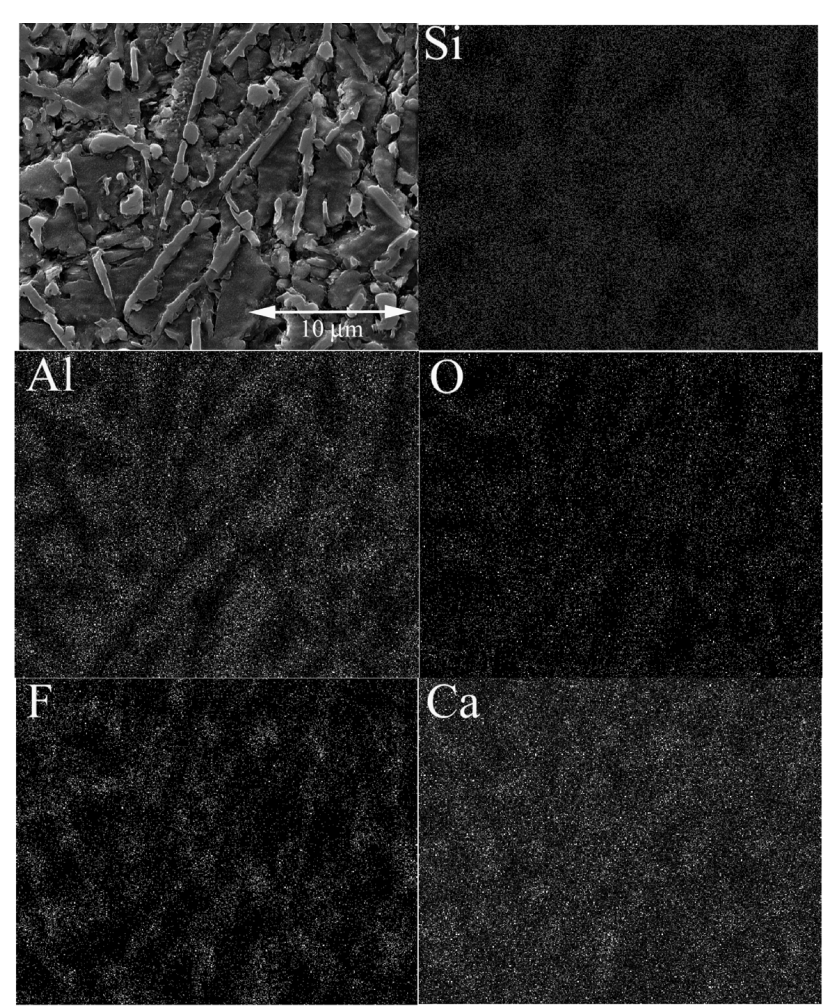

Fig. 6. SEM observations of cross-sections of slag 1 annealed at (b) $1025^{\circ} \mathrm{C}$.

ements of $\mathrm{Al}, \mathrm{Si}, \mathrm{O}$ and $\mathrm{Ca}$ were observed to co-exist.

In order to determine how the chemical composition influences the crystal phases, the glassy phases for slags No. 1, No. 2 and No. 3 were annealed at different temperatures for $12 \mathrm{~h}$ and analyzed by XRD. Figure 7(a) shows the XRD results of slag No. 1 annealed at $950^{\circ} \mathrm{C}, 1050^{\circ} \mathrm{C}$ and
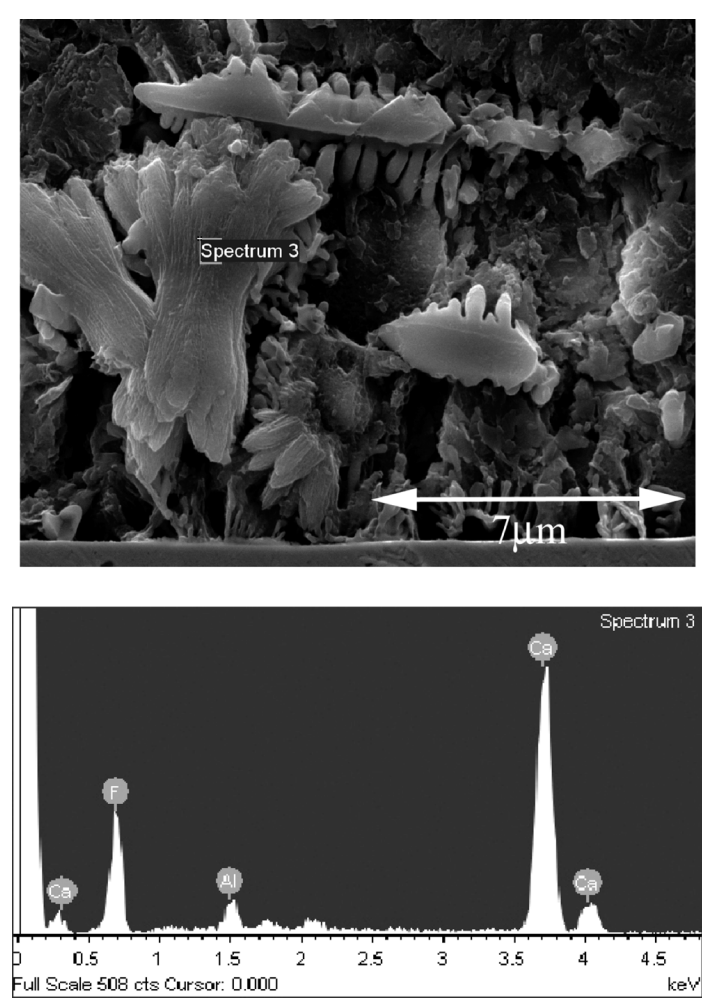

Fig. 6. SEM observations of cross-sections of slag 1 annealed at (c) $925^{\circ} \mathrm{C}$.

$1150^{\circ} \mathrm{C}$. It can be seen that there is no obvious difference in the crystal phases formed at different annealing temperatures. The main phases formed for slag No. 1 were found to be $\mathrm{Ca}_{2} \mathrm{Al}_{2} \mathrm{SiO}_{7}$ and $\mathrm{CaF}_{2}$, which is consistent with the SEM-EDS mapping results (Fig. 6). It is interesting to note that the corresponding phases formed for slag No. 2 are $\mathrm{Ca}_{4} \mathrm{Si}_{2} \mathrm{O}_{7} \mathrm{~F}_{2}$ and $\mathrm{CaF}_{2}$ (Fig. 7(b)). The crystalline phases for slag No. 3 are $\mathrm{Ca}_{4} \mathrm{Si}_{2} \mathrm{O}_{7} \mathrm{~F}_{2}$ and $\mathrm{CaMgSiO}_{4}$ (Fig. 7(c)). Therefore, a tendency that the precipitation of $\mathrm{CaF}_{2}$ and a change in the crystalline phase from $\mathrm{Ca}_{4} \mathrm{Si}_{2} \mathrm{O}_{7} \mathrm{~F}_{2}$ to $\mathrm{Ca}_{2} \mathrm{Al}_{2} \mathrm{SiO}_{7}$ was observed with an increasing addition of alumina. The reason could be that $\mathrm{Ca}_{2} \mathrm{Al}_{2} \mathrm{SiO}_{7}$ is thermodynamically more stable than $\mathrm{Ca}_{4} \mathrm{Si}_{2} \mathrm{O}_{7} \mathrm{~F}_{2}$ in the experimental temperature range. ${ }^{25,26)}$ This would predict the consumption of ion species containing $\mathrm{Al}^{3+}, \mathrm{Ca}^{2+}$ and $\mathrm{Si}^{4+}$ in order to form $\mathrm{Ca}_{2} \mathrm{Al}_{2} \mathrm{SiO}_{7}$, and the remaining liquid slag could be enriched in $\mathrm{F}$ which consequently could precipitate as $\mathrm{CaF}_{2}$ in the interdendritic zone. If alumina content is lower than $15 \mathrm{wt} \%, \mathrm{Ca}_{4} \mathrm{Si}_{2} \mathrm{O}_{7} \mathrm{~F}_{2}$ precipitates as a predominant crystal phase consuming $\mathrm{F}$ and $\mathrm{Ca}$, which results in the prevention of $\mathrm{CaF}_{2}$ precipitation. $\mathrm{Ca}$ was observed in the dendritic crystals annealed at $925^{\circ} \mathrm{C}$ (Fig. 6(c)). It is also noted that slag No. 1 containing the high alumina content exhibited the highest tendency to crystallize, but there was no evidence of alumina crystals formed in this investigation.

A comparison of SEM-EDS results with XRD indicates that the dendrite structure in Fig. 6 could be $\mathrm{Ca}_{2} \mathrm{Al}_{2} \mathrm{SiO}_{7}$, and the interdendritic regions are $\mathrm{CaF}_{2}$. It should be pointed out that $\mathrm{CaF}_{2}$ could precipitate during cooling process when the temperature was $1125^{\circ} \mathrm{C}$ and $1100^{\circ} \mathrm{C}$ for slag No. 1 and slag No. 2, respectively, or be formed during the isothermal process. This is consistent with the previous findings. ${ }^{27)}$ Further analysis indicated that $\mathrm{CaF}_{2}$ may not be the thermodynamic stable phase, which is dependent on the 

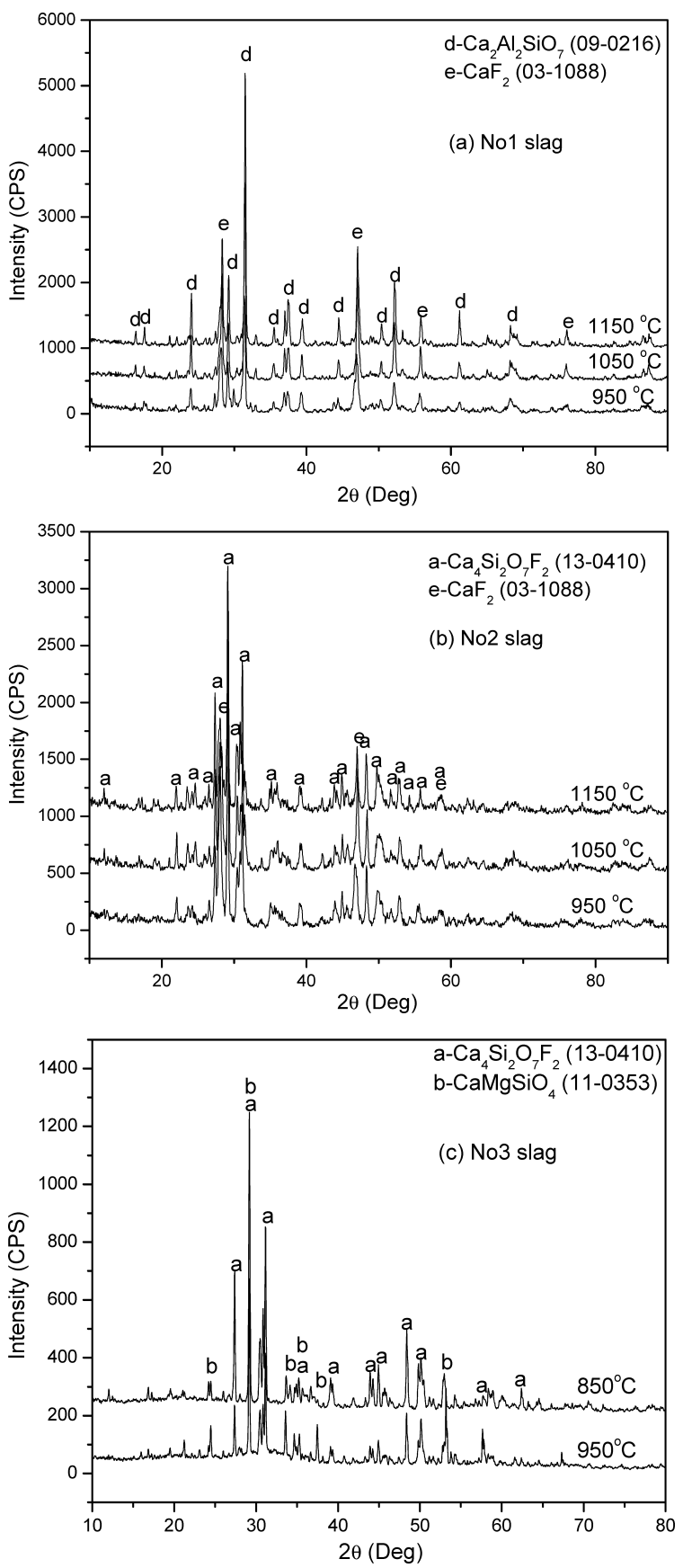

Fig. 7. XRD patterns of slags annealed at pre-set temperatures for $12 \mathrm{~h}$.

chemical compositions of slag, i.e., the crystal phases can change during crystallization process. For slags with low alumina content, the precipitated $\mathrm{CaF}_{2}$ could combine with $\mathrm{CaO}$ and $\mathrm{SiO}_{2}$ to form $\mathrm{Ca}_{4} \mathrm{Si}_{2} \mathrm{O}_{7} \mathrm{~F}_{2}$, i.e. $\mathrm{CaF}_{2}$ transforms during a long annealing process. However, $\mathrm{CaF}_{2}$ is a stable phase in the slag melts containing high alumina content. ${ }^{28)}$

\subsection{Heat Flux Measurements}

Figure 8 shows an example how the heat flux and thickness of slag film for slag No. 3 vary with time. As mentioned earlier, the heat flux can be divided into three stages. During the initial stage, the heat flux density is influenced by the principle of unsteady heat conduction, and heat transfer occurs between the copper and liquid slag during this period of solid slag deposition. Regular status stage is

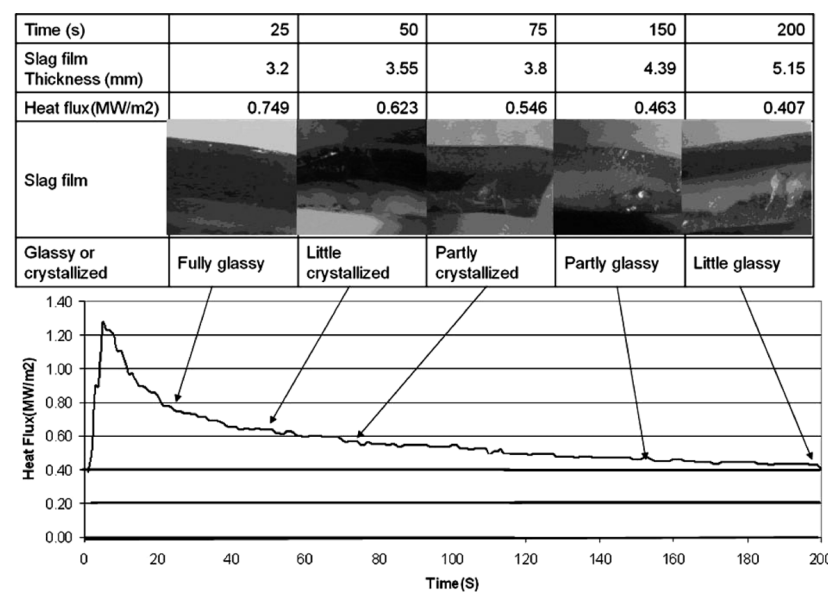

Fig. 8. Regular status stage and stable stage.

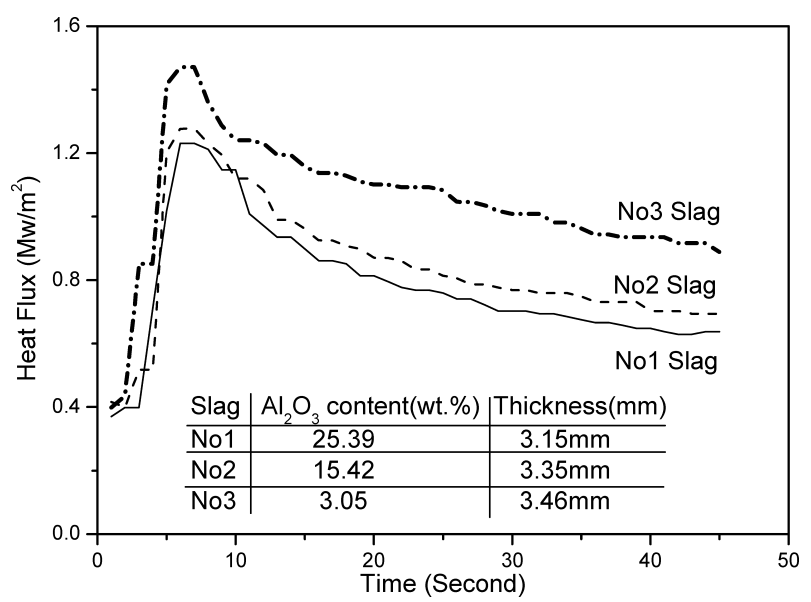

Fig. 9. Heat flux history of mold slags.

defined as the time from $t_{1}=7 \mathrm{~s}$ to $t_{2}=45 \mathrm{~s}$. The reason for choosing $t_{2}=45 \mathrm{~s}$ is that the residence time for the mold slag in the mold is about $45 \mathrm{~s}$ during the operational casting of TRIP steels. ${ }^{4)}$ The heat flux density decreases quickly after $t_{1}$ because of the increase in the solid slag film thickness (glass and/or crystalline) and the air gap formation of the $\mathrm{Cu}$ sensor-slag. Stable stage is therefore defined as the time after $t=45 \mathrm{~s}$. The heat transfer characteristics of the slag film shows mainly the crystallization of the solid slag film, the increasing thickness of the solid slag film with decreasing furnace temperature about $10-15 \mathrm{~s}$ later after immersing copper sensor and air gap change. Figure 8 also includes the thickness of slag film that was interrupted at different time intervals, as expected, the thickness of slag film is increased with increasing of time. Further analysis indicated that the crystallization had not occurred for $25 \mathrm{~s}$ after immersing copper sensor. As the time progresses further, the thickness of the crystallized layer and solidified slag increased but at a slow rate resulting in a gradually decreasing change in the heat flux, corresponding to the third stage.

The results from the heat flux measurements for the 3 slags are shown in the Fig. 9. As can be seen, the heat flux takes $7 \mathrm{~s}$ to reach the maximum values, which are $1.23,1.28$ and $1.47 \mathrm{Mw} / \mathrm{m}^{2}$ for slags No. 1 , No. 2 and No. 3, respectively, followed by a rapid decrease, and then it reached the steady values. The average heat fluxes are $0.81,0.87$ and 
$1.08 \mathrm{Mw} / \mathrm{m}^{2}$ for slags No. 1, No. 2 and No. 3, respectively. As expected, the heat flux increased with basicity and alumina content of mold slag decreased. The thickness of slag film was measured and included in Fig. 9, and was found to increase with decreasing of basicity and alumina content. The slag film layers of slags taken after $45 \mathrm{~s}$ immersion were characterized through SEM, and the results are shown in Fig. 10. It can be seen that slags No. 1, No. 2 and No. 3 have shown a clear difference among the crystallization tendencies. The SEM images of slag film layer for slag No.
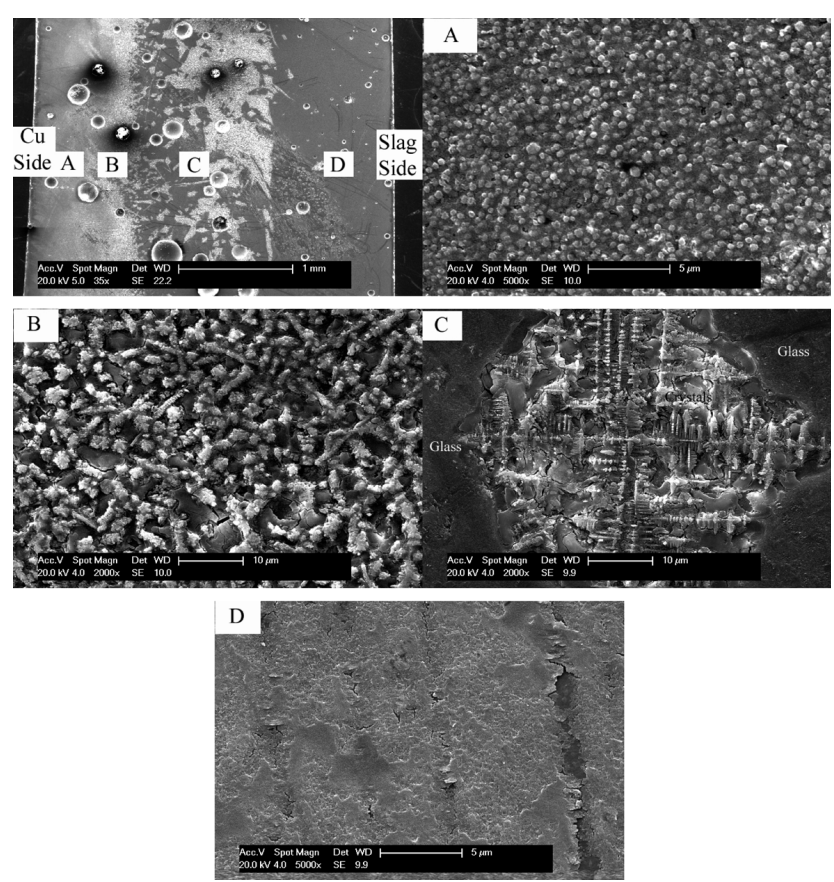

(a)

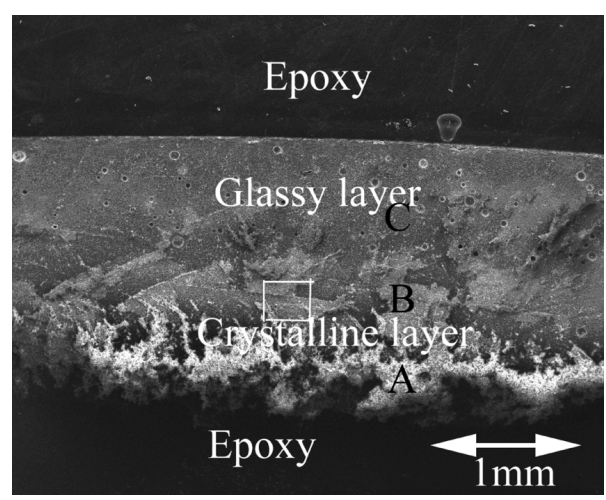

(b)

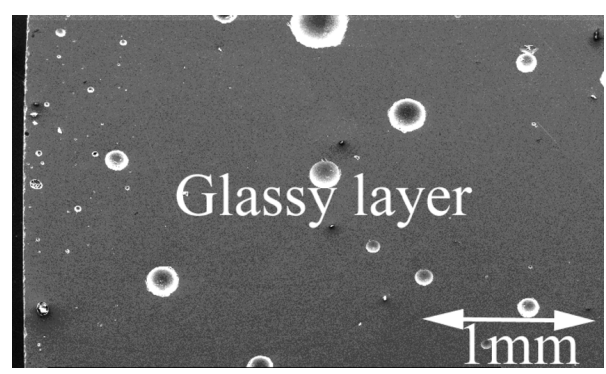

(c)

Fig. 10. SEM photographs of cross sections of (a) No. 1, (b) No. 2 and (c) No. 3 slags after $45 \mathrm{~s}$ immersion.
1 indicated that there were four different crystalline layers that could be distinguished (Fig. 10(a)). Layers A and B in the figure are crystalline layer, and layer $\mathrm{C}$ is composed of mixed crystalline and glassy phases, and layer D is a glassy phase layer. A, B and C layers are likely be have formed at different temperatures, where layer $\mathrm{A}$ is composed of small equiaxed particles, layer B is a mixture of equiaxed particles and dendrite crystals and the structure of this layer is coarser than that of layer A, and layer $\mathrm{C}$ mainly consists of dendrite crystals with fine crystal tips. Structure of slag film for slag No. 2 is similar with that of slag No. 1, which consists of 3 sublayers (labeled A, B and C in Fig. 9(b)). Figure 10 (c) presents the structure of slag film layer of slag No. 3, as expected, no crystalline layer was observed. The structure of the layer indicates the different crystallization characteristics.

In order to understand the crystallization of mold slags
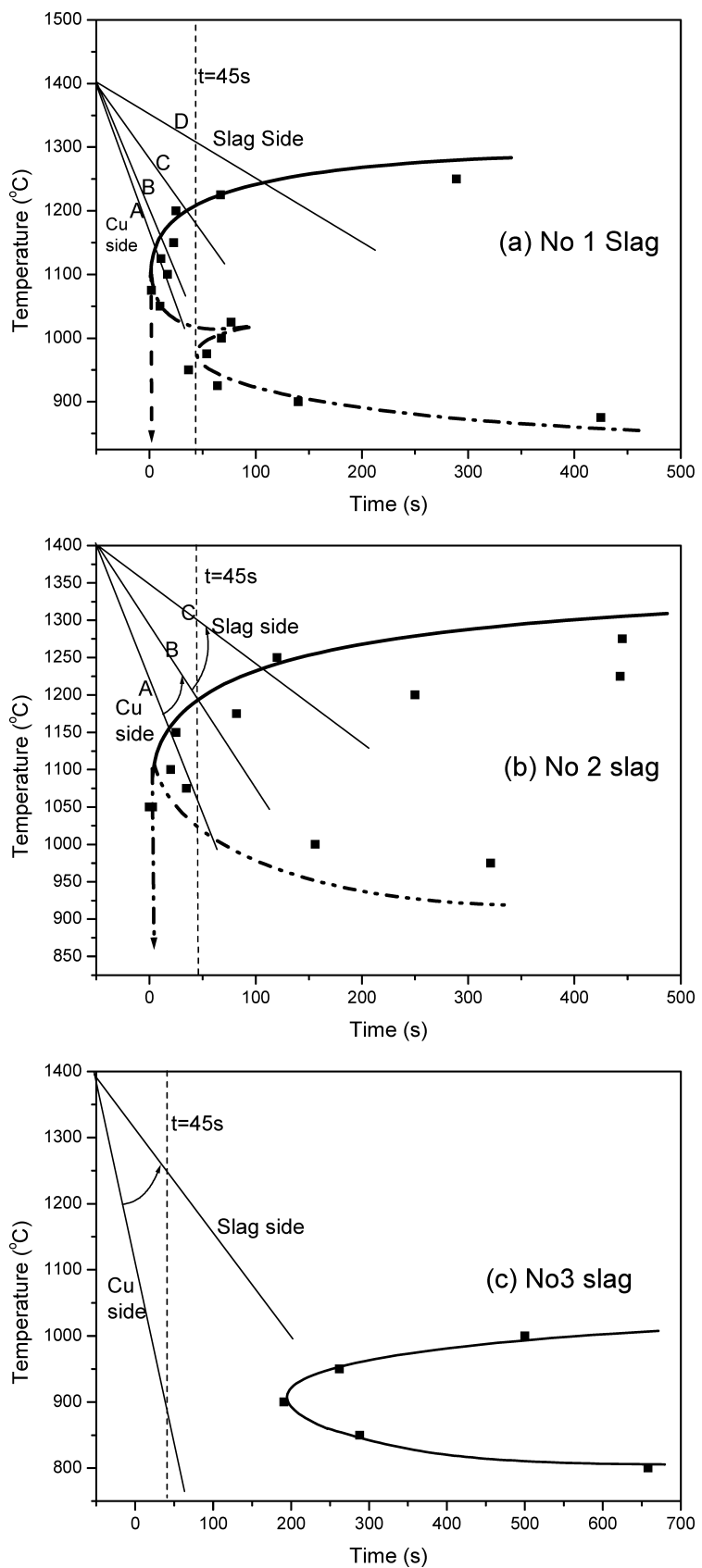

Fig. 11. Cooling rate versus time (a) slag No. 1, (b) slag No. 2 and (c) slag No. 3. 
and the location of the crystalline layers, it is necessary to combine the TTT-diagrams to analyze the crystallization. It is well known from classical nucleation theory that the onset of crystallization of mold slags is dependent on the cooling rates. ${ }^{29)}$ It should be pointed out that the cooling rate varies with location, i.e., the cooling rate near the copper sensor is fast and is slow at the location away the copper sensor. The cooling rate versus the time is labeled with the TTT-diagrams, as can be seen from Fig. 11. ${ }^{30,31)}$ These lines show the cooling rate in different layers in the slag film as shown in Figs. 10(a) and 10(b), where line A indicates a fast cooling rate in the layer $\mathrm{A}$ and line $\mathrm{D}$ and line $\mathrm{C}$ indicate the slow cooling rates in the layer D for Fig. 10(a) and in the layer $\mathrm{C}$ for Fig. 10(c). The cooling rates intersecting the TTT diagrams within $45 \mathrm{~s}$ indicated that the crystallization can occur, which results in the observation of crystalline layers. These findings provide an explanation to some of the most important observations in last paragraph associated with Fig. 10:

(1) The slag film consists of several sublayers for slags No. 1 and No. 2, but no crystallization was observed for slag No. 3. This suggests that for this slag the cooling rate was such that the TTT diagram was not intersected ( $45 \mathrm{~s})$ for slag No. 3.

(2) The structures of crystals are dependent on the distance from the copper sensor. This is because of the differences in cooling rates. The layer near the copper sensor, such as layer A for slags No. 1 and No. 2, has the small equiaxed crystals because these places have the fastest cooling rates. With decreasing of the cooling rate, the crystals formed are coarser, and dendritic crystals are formed. These phenomena can be explained by nucleation and growth rates. On the copper sensor side, the nucleation rate is high, while the growth rate is low, resulting in the structure with many small crystals. With decreasing cooling rate, the growth rate is higher while the nucleation rate is lower, resulting in fewer but larger crystals.

(3) Layer C for slag No. 1 has a mixture of crystalline and glassy phases, indicating that the cooling rate at that place is favorable to form a partly crystalline region.

(4) Pores were observed for all slag films, which may be due to the shrinkage during cooling.

\subsection{Effect of Alumina Content in Slag No. 3}

The heat fluxes that were measured for the three slags based on the No. 3 slag with different alumina contents are shown in Fig. 12. The heat flux was found to decrease with increasing of alumina addition. As was found when comparing slags $1-3$, the alumina content affected the heat flux by decreasing it with increasing of crystalline tendency. If the heat flux decreases, the solidified shell thickness of steel would be expected to become thinner during continuous casting. The decrease in heat flux could be due to the variation of slag structure with $\mathrm{Al}_{2} \mathrm{O}_{3}$ addition. It is well know that $\mathrm{Al}_{2} \mathrm{O}_{3}$ is an amphoteric oxide. ${ }^{32)}$ In the aluminosilicate molten slags, the $\mathrm{Al}$-ion complex is generally present as $\left[\mathrm{AlO}_{4}\right]^{5-}$ when the $\mathrm{Al}_{2} \mathrm{O}_{3}$ content is less than 10 mass $\%$ at a fixed $\mathrm{CaO} / \mathrm{SiO}_{2}$ ratio. In this case, the $\left[\mathrm{AlO}_{4}\right]^{5-}$ tetrahedron acts as the network former through joining itself into the $\left[\mathrm{SiO}_{4}\right]^{4-}$ networks. This process needs the additional

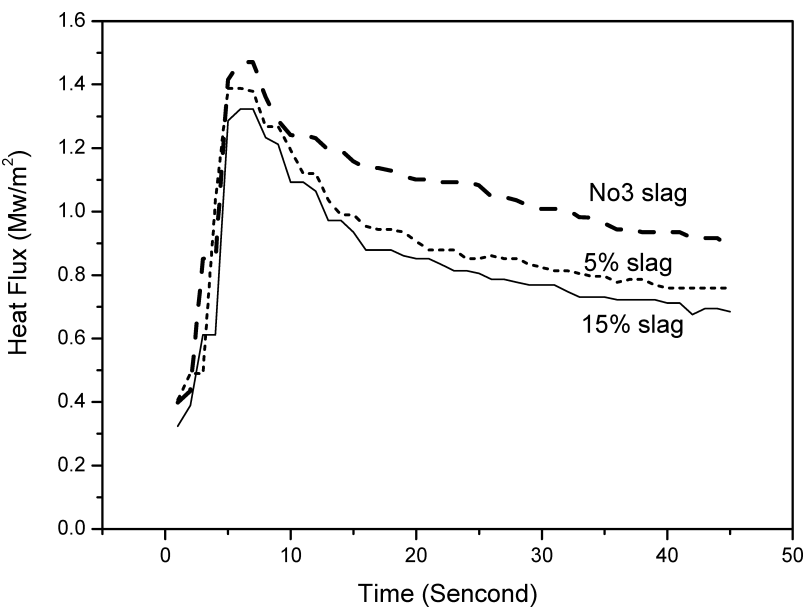

Fig. 12. The change of heat flux according to alumina pick-up amount.

cations such as $\mathrm{Ca}^{2+}$ or $\mathrm{Na}^{+}$to make the electrical charge balance. ${ }^{33)}$ When the $\mathrm{Al}_{2} \mathrm{O}_{3}$ content is larger than 10 mass $\%$, octahedral would be present, i.e., the alumina would act as the network breaker. These structural changes in aluminosilicate melts could have a remarkable influence on the thermophysical properties. Under the present experiment, the alumina contents of slags No. 3 and No. $3+5 \mathrm{Al}_{2} \mathrm{O}_{3}$ are less than this inflection point, i.e., $\mathrm{Al}_{2} \mathrm{O}_{3}$ acts as network former. This would enhance the viscosity with increasing alumina content, resulting in the decrease of mobility of diffusing species. However, the crystallization tendency was observed to increase with increasing of alumina content. This suggests that long range diffusion of ion complex may not be the most pertinent factor that controls crystallization in the present experiments. As per the aforementioned discussions, a trend to form high melting point crystals such as $\mathrm{Ca}_{2} \mathrm{Al}_{2} \mathrm{SiO}_{7}$ with increasing alumina content was observed. ${ }^{28)}$ This might partly explain the increase in crystallization tendency with increasing alumina content. ${ }^{4}$ The heat flux was correspondingly decreased with increasing alumina content.

\section{Conclusions}

In the present paper, two different laboratory methods, Confocal scanning laser microscope (CSLM) and heat flux simulator were employed to study the crystallization properties of mold fluxes used in casting of TRIP steels. The conclusions are as follows,

(1) The TTT diagrams were established through in-situ crystallization observations with CSLM, and the crystallization temperature ranges as well as crystallization tendency increased, whereas the incubation time decreases with increasing of basicity and alumina content.

(2) The precipitated crystalline phases are $\mathrm{CaMgSiO}_{4}$ and $\mathrm{Ca}_{4} \mathrm{Si}_{2} \mathrm{O}_{7} \mathrm{~F}_{2}$ for slag No. 3, and the increasing addition of alumina content induces a transformation of crystalline phase from $\mathrm{Ca}_{4} \mathrm{Si}_{2} \mathrm{O}_{7} \mathrm{~F}_{2}$ to $\mathrm{Ca}_{2} \mathrm{Al}_{2} \mathrm{SiO}_{7}$.

(3) The heat fluxes of mold slags were measured by a heat flux simulator, and were found to increase with decreasing of basicity and alumina content. The heat flux was found to decrease as alumina was added to the the glassy No. 3 slag. 


\section{Acknowledgement}

Financial supports from the Center for Iron and Steelmaking Research, Carnegie Mellon University (CISR) and from National Natural Science Foundation of China (50902003) as well as The National Basic Research Program (2007CB613608) are gratefully acknowledged.

\section{REFERENCES}

1) M. Wolf: ISS Process Technol. Conf., 13 (1995), 99.

2) K. C. Mills, P. Grievson, A. Osuanya and S. Bacha: TIM-Continuous Casting, (1985), 571.

3) R. Taylor and K. C. Mills: Ironmaking Steelmaking, 15 (1988), 187.

4) K. C. Mills: Mold Powders for Continuous Casting. Casting Volume, ed. by K. C. Mills, The AISE Steel Foundation, Pittsburgh, PA, (2003), Chapter 8, 1.

5) H. Nakada and K. Nagata: ISIJ Int., 46 (2006), No. 3, 441.

6) C. Orrling: Ph.D Thesis, Carnegie Mellon University, (2000), 157.

7) Y. Kashiwaya, C. E. Cicutti, A. W. Cramb and K. Ishii: ISIJ Int., 38 (1998), 348.

8) S. Ohmiya: Ironmaking Steelmaking, 10 (1983), 24.

9) A. Yamauchki, E. Sorimachti and O. Sakura: ISIJ Int., 33 (1993), 140.

10) Z. Cheng, W. Chen and L. Li: J. Univ. Sci. Tech. Beijing, 25 (2003), No. 6, 524

11) Y. Vermeulen, E. Divry and M. Rigaud: Can. Metall. Q, 43 (2004), No. 4, 527.

12) G. Wen, S. Sridhar, P. Tang, X. Qi and Y. Liu: ISIJ Int., 47 (2007), 1117.

13) M. Takahashi, H. Yoshida and S. Hiwatashi: Int. Conf. on TRIPAided High Strength Ferrous Alloys, ed. by B. C. De Cooman,
Wissenschaftsverlag Mainz GmbH, Aachen, (2002), 103.

14) B. Saurhammer, D. Senk and E. Schmidt: Metall. Mater. Trans. B, 36 (2005), 324.

15) B. L. Jones and P. N. Jones: Scr. Metall., 8 (1974), 445.

16) W. L. Wang, K. Blazek and A. Cramb: Metall. Mater. Trans. B, 39 (2007), 66.

17) Z. T. Zhang, G. Wen, P. Tang and S. Sridhar: ISIJ Int., 48 (2008), No. 6, 745 .

18) F. Shahbazian, S. Du and S. Seetharaman: ISIJ Int., 42 (2002), 155.

19) F. Shahbazian, S. Du and S. Seetharaman: ISIJ Int., 39 (1999), 687

20) E. D. Schmidt, E. B. Damn and S. Sridhar: Metall. Mater. Trans. A, 38 (2007), 244.

21) H. Yin, T. Emi and H. Shibata: Acta Mater, 47 (1999), 1523.

22) M. Fonseca and O. Afrange: Proc. of 5th Int. Conf. on Molten Slags, Fluxes and Salts, ISS, Warrendale, PA, (1997), 851.

23) S. Andrei and H. Lauri: Steel Res. Int., 77 (2006), 803.

24) M. Persson, S. Sridhar and S. Seetharaman: ISIJ Int., 47 (2007), 1711.

25) H. Fukuyama, H. Tabata and K. Nagata: Metall. Mater. Trans. B, 34 (2003), 307.

26) I. Barin: Thermochemical Data of Pure Substance, VCH, New York, (1989).

27) W. Wang, K. Blazek and A. Cramb: Metall. Mater. Trans. B, 39 (2008), 66.

28) Z. Zhang, G. Wen, J. Liao and S. Sridhar: Int. Steel Res., (2010) Accepted.

29) W. Kurz and D. J. Fisher: Fundamental of Solidification, 3rd ed., Trans. Tech. Publications, Switzerland, (1992), 293.

30) J. L. Lee, Y. T. Pan and K. C. Hsieh: Mater. Trans. JIM, 39 (1998).

31) E. Scheil: Arch. Eisenhüttenwes, 8 (1935), 565.

32) E. T. Turkdogan and P. M. Bills: Ceram. Bull., 39 (1960), 682.

33) K. C. Mills: Slag Atlas, 2nd ed., Verein Deutscher Eisenhuttenleute (VDEh), (1995), 2. 